Ensino, Saúde e Ambiente-Vs (3), pp. 1-14. Dezembro, 2015

\title{
EDUCAÇÃO FÍSICA ESCOLAR, INTERCULTURALIDADE E SAÚDE: UMA ARTICULAÇÃO NECESSÁRIA
}

\section{SCHOOL PHYSICAL EDUCATION, INTERCULTURALITY AND HEALTH: A RELATIONSHIP NECESSARY}

\author{
André Pereira Triani ${ }^{1}$, Ricardo Alves da Fonseca ${ }^{2}$, Fabiana Letícia Sbaraini ${ }^{3}$ \\ Universidade Federal de Roraima, Centro de Educação, andretriani@gmail.com \\ Universidade Federal de Roraima, Programa de Pós-Graduação em Ciências da Saúde, \\ ricardoalvesdafonseca@yahoo.com.br \\ Instituto Federal de Educação, Ciência e Tecnologia de Roraima, Curso de Licenciatura em Educação \\ Física, fabisbara@yahoo.com.br
}

\section{RESUMO}

Desde o desenvolvimento da Educação Física como disciplina no Brasil, ela passou por várias transformações, principalmente na sua metodologia de ensino e nos objetivos da sua prática, iniciando com uma concepção extremamente reducionista até chegar a ideais mais abrangentes com uma articulação entre educação, cultura e saúde. Com isso este artigo visa discutir as dificuldades e potencialidades do ensino da Educação Física de forma a contemplar uma visão integradora entre as diferenças sociais e culturais existentes na escola e concomitantemente trabalhar questões de educação e saúde. Percebeu-se que a Educação Física escolar em nosso país tem um enorme potencial do ponto de vista intercultural não somente para o estímulo da prática regular de atividades físicas e promoção da saúde mas também para o desenvolvimento de uma educação multidimensional formando cidadãos mais críticos e socialmente participativos com uma maior capacidade de aprender com o outro e com ele produzir coletivamente numa realidade em que diferentes pontos de vista sejam conhecidos e utilizados como base o desenvolvimento da cidadania.

Palavras-chave: Atividade Física; Cultura; Educação; Saúde.

\begin{abstract}
Since the development of physical education as a subject in Brazil, it has undergone several transformations, especially in its teaching methods and goals of their practice, starting with an extremely reductionist conception to reach more comprehensive ideal with a link between education, culture and health. Thus this paper discusses the difficulties and potential of the teaching of physical education in order to contemplate an integrated view of the social and cultural differences within the school and concurrently work of education and health issues. It was noticed that the School Physical Education in our country has huge potential intercultural point of view not only to the stimulus of regular physical activity and health promotion but also for the development of a multidimensional education forming more critical citizens and socially participatory with a greater ability to learn from the other and with it collectively produce a reality in which different views are known and used as a basis the development of citizenship.
\end{abstract}

Keywords: Physical Activity; culture; education; Health. 
Ensino, Saúde e Ambiente-V8 (3), pp. 1-14. Dezembro, 2015

\section{INTRODUÇÃO}

As primeiras manifestações da cultura corporal em nosso país remontam ao período do Brasil colônia através dos movimentos naturais dos povos indígenas incluindo suas danças e jogos e posteriormente pela criação da capoeira pelos escravos negros. Atualmente nota-se que desde então já havia uma diversidade de práticas corporais ligadas as culturas presentes em nosso país. Contudo, esta variedade de manifestações relacionadas ao movimento corporal foi negligenciada por um longo tempo, passando a ser discutida muito recentemente.

A Educação Física chegou como disciplina ao Brasil no início do século XIX através da implantação dos métodos ginásticos europeus. Até o início da década de 1980 a Educação Física em nosso país passou por uma série de mudanças no que diz respeito aos seus métodos e objetivos de atuação, mas sempre enxergando o homem apenas do ponto de vista biológico, procurando preparar o corpo físico. De acordo com Oliveira e Daolio (2011), tratava-se de uma prática que não considerava o contexto dos sujeitos e que tinha como preocupação a educação do físico, pautada numa concepção natural de ser humano.

As discussões em torno da diversidade cultural no campo da Educação Física tiveram início na década de 1980. A partir de então a naturalização da Educação Física começou a ser questionada e começou a se pensar no ser humano não somente como um ser biológico mas também como um ser social e cultural. Este período foi marcado pela inserção das ciências humanas no cenário acadêmico da Educação Física levando a uma crise epistemológica que culminou com a ampliação da visão da área e de sua ação pedagógica (OLIVEIRA e DAOLIO, 2011).

Sem deixar de tratar do corpo físico, mas também incluindo nas suas práticas uma visão cultural do homem a Educação Física passa a lidar com inúmeros questionamentos de como trabalhar o componente biológico integrado ao fator social que caracteriza o homem de forma a desenvolver uma ação que promova essa interação de forma efetiva, levando em consideração os diversos contextos socioculturais existentes no Brasil. A partir daí, pretende-se abordar neste ensaio uma reflexão das práticas de uma Educação Física que contemple seu objetivo educacional e de promoção da saúde discutindo a interculturalidade como uma possibilidade de efetivação dessas 
ações.

\section{EDUCAÇÃO FÍSICA ESCOLAR E INTERCULTURALIDADE}

A cultura é uma característica comum a todas as populações, sendo que cada uma delas manifesta a sua de forma única. Além disso é um processo dinâmico que traduz as mudanças ocorridas no seio da sociedade ao longo do tempo. As crianças e adolescentes, também estão inseridos dentro de um contexto cultural que tem como núcleo a família, se estendendo às demais pessoas que interagem a sua volta. Sendo assim a escola é um espaço de grande influência na manifestação cultural de crianças e adolescentes além de ser o local onde as culturas que cada sujeito carrega encontram-se, podendo estas interagirem ou divergirem, de acordo com o que é estimulado pelos educadores.

Apesar disso a escola, historicamente baseia-se em um ensino monocultural, o que tende a oprimir e ofuscar as particularidades do outro, sendo que este é visto como uma pessoa que precisa ser educada dentro da cultura considerada superior pelo currículo escolar. Em um estudo de 2011, Oliveira e Daolio, afirmam que os conhecimentos das culturas hegemônicas são enfatizados nas propostas curriculares, o que silencia e/ou oculta outras vozes culturas presentes na sociedade.

A parir disso, passou-se a ser discutido com maior abrangência a valorização das diferenças encontradas na escola, numa tentativa de superar os problemas educacionais relacionados com uma concepção pedagógica unitária e excludente. Reconhecer e trabalhar as potencialidades de cada contexto social e cultural existente no ambiente escolar parece uma forma eficaz de transpor um modelo pedagógico que visa homogeneizar o ensino e a aprendizagem sem levar em conta a significação das experiências vividas por cada educando.

Nos últimos anos, sofrendo o efeito do progressivo multiculturalismo da sociedade, as escolas passaram a confrontar-se com a realidade desajustada dos currículos etnocêntricos e monoculturais que as caracterizam. Este desajuste, aliado aos ideais democráticos que passaram a orientar as políticas educativas que assumiram o princípio da "escola para todos", foi evidenciando a necessidade de analisar o currículo e nele intervir diante das condições oferecidas aos diferentes grupos que passaram a frequentar os bancos escolares (NEIRA, 2008, p.3). 
Um passo importante nesse sentido é o reconhecimento do multiculturalismo existente nas escolas do país. $\mathrm{O}$ discurso recorrente tanto no meio acadêmico quanto nos setores governamentais proclama o reconhecimento da diversidade cultural e a necessidade da reconstituição das práticas escolares de forma a valorizar as diferenças (NEIRA, 2009). O termo multiculturalismo tem um caráter, de acordo com Rangel et al. (2008), polissêmico configurando-se como sendo a coexistência de várias culturas em um mesmo território. Ou seja, ele traduz a necessidade de reconhecer a sociedade como um grupo formado por diversas identidades, considerando a diversidade de raça, gênero, classe social e manifestações culturais.

A valorização e o entendimento do multiculturalismo, dentro de um contexto onde os princípios universais de igualdade vem sendo negados historicamente, é um importante passo para um movimento de garantia do direito à cidadania de forma individual e coletiva. Porém deve-se tomar cuidado para que, ao reconhecer o multiculturalismo, não sejam formados "guetos culturais" onde apenas se reconhece a cultura do outro sem que haja um diálogo e uma interação entre elas, o que pode mascarar a discriminação.

A partir daí, na tentativa de superar o modelo educacional pautado em um currículo hegemônico, surge a ideia da educação intercultural, baseada nos princípios do interculturalismo que implica em não apenas reconhecer a cultura do outro, mas também em proporcionar o diálogo entre essas diferentes culturas, procurando transcender a uma realidade sem discriminação e de valorização intercultural. De acordo com Fleuri (2003), a ideia de interculturalidade está relacionada a convivência democrática entre diferentes grupos e culturas que estimula percepções positivas da pluralidade social e cultural, respeitando as diferenças e reconhecendo a paridade de direitos.

Nesse sentido o ambiente escolar precisa ser um espaço que promova o diálogo, que possibilite o acesso ao conhecimento através do compartilhamento de valores e atitudes, concordando com Rangel et al. (2008), onde afirma que a escola deve ser um ambiente de inclusão, sendo considerada a partir do respeito e da valorização das diferenças culturais.

Nessa esteira, a educação intercultural calca seus pressupostos, os quais apontam, não somente, para existência das diferenças, mas também para seu 
enlace com a aprendizagem, fazendo com que o educando apreenda o conhecimento do outro, do diferente e com ele estabeleça um diálogo profícuo e mútuo, no qual as possibilidades não se encerram a partir de uma única visão (OLIVEIRA e DAOLIO, 2011, p.4).

A Educação Física, talvez mais do que os outros campos da educação, enfrenta um conflito no sentido da diversidade cultural existente nas escolas. A partir do momento em que a Educação Física deixou de visualizar o homem apenas do ponto de vista biológico e passou a considerá-lo também como um ser social e cultural, começou a se deparar com questionamentos e reflexões acerca da diversidade de características socioculturais das pessoas e de como trabalhar com isso de forma a contribuir para o seu desenvolvimento.

\footnotetext{
Considerando a Educação Física enquanto componente curricular que valoriza sua práxis e se compromete com a socialização e ampliação crítica do universo cultural dos estudantes, a perspectiva cultural contribui com o esforço coletivo de construir uma prática pedagógica voltada para a transformação social, ao formar sujeitos que reconheçam, valorizem e dialoguem com a multiplicidade identitária que coabita a sociedade. Além de permitir a reflexão crítica da realidade, espera-se que as atividades de ensino se constituam como um canal privilegiado de produção de cultura, onde os sentimentos, a criatividade, o lúdico e o patrimônio sócio-histórico relacionado à corporeidade de todos os grupos sociais sejam contemplados e respeitados (NEIRA, 2009, p.86).
}

Para que isso ocorra é preciso um mergulho profundo na realidade do outro. De acordo com Gusmão (2003) apud Rangel et al. (2008) é necessário olhar para a sociedade onde o grupo ou o indivíduo estão e vivem para que assim as diferenças ganhem sentido e definam o papel da alteridade nas relações sociais entre os sujeitos.

As aulas de Educação Física têm um grande potencial para a concretização dessas ideias. Nelas é possível reunir práticas que refletem os diversos contextos socioculturais vivenciados pelos alunos. Como exemplo aparece a figura dos jogos populares, das danças e de outras práticas corporais que variam em função da realidade em que historicamente foram criadas e que a partir do dinamismo cultural sofreram alterações baseadas nas transformações sociais que lhes eram contemporâneas. Essas atividades possuem uma enorme capacidade de fazer com que o aluno vivencie uma realidade sociocultural diferente da qual ele é originário, proporcionado um momento de reflexão e diálogo com este outro universo. Neste sentido, Rangel et al. (2008, p.164) acrescentam que: 


\begin{abstract}
...não basta escolher e ministrar tais temas. A forma como o tratamento metodológico ocorrerá no dia a dia também pode refletir a opção pelo interculturalismo. Assim, não basta, por exemplo, escolher uma dança que represente a cultura de um país e não contextualizá-la. Cada opção de conteúdo possibilita uma discussão, um esclarecimento e, talvez, uma nova visão sobre o assunto.
\end{abstract}

Os autores citando outros estudos realizados sobre o tema, complementam ainda colocando que existem:

\begin{abstract}
...várias possibilidades de se trabalhar com esta temática. A mais simples delas é vivenciar as diferentes "manifestações da cultura corporal". Um exemplo seria a experimentação de danças típicas dos diversos grupos étnicos que compõem o Brasil, demonstrando assim a riqueza e a diversidade de expressões existentes. $\mathrm{O}$ mesmo se aplicaria às ginásticas e às lutas, que ainda conseguem manter suas raízes ligadas às regiões de origem, o que também possibilitaria o conhecimento por parte dos alunos da diversidade cultural, ex.: Capoeira - Brasil/África, Judô, Karatê - Ásia. Entretanto, conforme destacado anteriormente não basta apenas vivenciar estas diferentes manifestações culturais, mas, também que a partir delas se questione e se discuta as raízes (condicionantes históricas) destas, procurando afastar-se da manutenção, valorização e criação de estereótipos. Trata-se neste caso de buscar ancorar socialmente a questão, ou seja, explicitar as origens e as construções de determinados conceitos (MOREIRA; CANDAU, 2003 apud RANGEL et al. 2008, p.164).
\end{abstract}

Isso evidencia a capacidade da educação, e principalmente da Educação Física que utiliza de uma abordagem intercultural, na formação de jovens com um pensamento crítico sobre si e sobre os demais a sua volta. De acordo com Helman (2009) onde afirma que na construção da cultura da infância, tanto em casa quanto na escola, as crianças não são apenas receptores passivos do processo, mas também desenvolvem suas próprias crenças e linguagem e contribuem para o desenvolvimento de sua própria identidade, percebe-se a importância dessa criticidade proporcionada por uma abordagem educacional intercultural na estruturação de relações cujo o respeito e a interação mutua pela realidade sociocultural do outro parte de dentro como um processo natural construído ao longo da formação desse sujeito.

Contudo, para que isto se torne uma realidade cada vez mais presente nas escolas do país é preciso que alguns fatores sejam modificados, principalmente no que tange aos currículos escolares e à formação do profissional. Partindo então da prerrogativa de que todo currículo é uma construção social, a sua elaboração ou modificação está condicionada à influências dos pressupostos teóricos que 
fundamentam os conhecimentos a serem ensinados e que subsidiam a ação pedagógica (SILVA, 1999 apud NEIRA, 2009). A partir daí, um currículo que sustente a importância da interculturalidade nas aulas de Educação Física

\begin{abstract}
...deve promover uma compreensão sócio-histórico-política sobre as manifestações da cultura corporal, visando alcançar uma participação mais intensa e digna na esfera social. Para tanto, as atividades de ensino deverão contemplar experiências que viabilizem tanto a prática das manifestações corporais presentes no universo cultural próximo e afastado, quanto a reflexão crítica acerca das diversas formas de representação cultural veiculadas pelas brincadeiras, danças, mímicas, cantigas e oferecer a cada criança a oportunidade de posicionar-se enquanto produtora de cultura corporal. O que se pretende é proporcionar a enunciação, por meio da tematização das manifestações corporais, da voz de várias culturas infantis no tempo e no espaço - da família, bairro, cidade, estado, país, a internacional, sulista, nortista, nordestina, urbana, rural, afro, indígena, imigrante e tantas outras que coabitam a sociedade brasileira contemporânea, além de problematizar as relações de poder presentes nas questões de gênero, etnia, religião, classe, idade, consumo, local de moradia, tempo de escolarização, ocupação profissional e outras que costumeiramente marcam as práticas corporais (NEIRA, 2009, p.87).
\end{abstract}

Outro ponto fundamental é a formação acadêmica do profissional de Educação Física. Essa mudança de perspectiva educacional daquela hegemônica monocultural para uma que contemple as potencialidades da inter-relação entre os diferentes contextos existentes na escola é um processo bastante complexo, que necessita de profissionais engajados nessa missão e que possuam condições para implementar tais concepções. Isso deve ter início primordialmente na academia, onde a sua formação também deve ser multi e intercultural, aproximando a realidade da teoria, tornando a vivência e a reflexão sobre a diversidade sociocultural um ponto marcante dessa formação (RANGEL et al. 2008).

Um profissional de Educação Física "concebido" dentro de uma realidade acadêmica que preceitua a interculturalidade como forma de ser e de agir, será capaz de identificar, refletir e utilizar as potencialidades de cada universo cultural ampliando significativamente seu repertório de intervenção, bem como a efetividade desta, em um mundo que clama pelo reconhecimento da sua diversidade.

Este profissional além de representar uma Educação Física comprometida com o desenvolvimento sociocultural para a formação de cidadãos reflexivos, críticos e conscientes por meio das práticas corporais, também é responsável por utilizar dessas mesmas práticas para fomentar discussões e estimular atitudes no que diz respeito a uma 
ação de educação em saúde. A partir daí, torna-se interessante que se discuta em torno das possibilidades carregadas pela interculturalidade, como uma maneira de se pensar em promoção de saúde por meio de uma cultura corporal desenvolvida a partir das especificidades das diversas culturas que coabitam o mesmo espaço. Neste sentido a interculturalidade apresenta-se como um conceito que deve ser levado em consideração nas práticas desse profissional, sejam elas relacionadas com um objetivo educacional ou com a finalidade da promoção da saúde através da atividade física.

\section{ATIVIDADE FÍSICA E SAÚDE DENTRO DA PERSPECTIVA DA EDUCAÇÃo FÍSICA INTERCULTURAL}

A atividade física é citada como um instrumento de recuperação, manutenção, e promoção da saúde desde os textos clássicos gregos, romanos e orientais (Matsudo et al., 2002). No entanto, apenas recentemente, através de inúmeros estudos epidemiológicos, essa associação vem sendo demonstrada e comprovada com maior clareza. As pesquisas indicam que quanto mais ativa uma pessoa é, menos limitações físicas ela tem, maior é a sua capacidade funcional e melhor é a sua aptidão física, sendo que o sedentarismo é um contribuinte em potencial para o desenvolvimento de diversos transtornos, tanto de ordem biológica quanto psicológica. De acordo com Glaner (2003), a prática regular de atividade física é fundamental para minimizar o risco de incubação e desenvolvimento precoce de doenças crônico degenerativas, possibilitando uma longevidade com maior qualidade de vida. Ainda em relação aos benefícios advindos com a prática regular de atividades físicas, Franchi et al. (2005, p.154) colocam que:

\footnotetext{
A prática de atividade física também promove a melhora na composição corporal, a diminuição de dores articulares, o aumento da densidade mineral óssea, a melhora da utilização de glicose, a melhora do perfil lipídico, o aumento da capacidade aeróbia, a melhora de força e de flexibilidade e a diminuição da resistência vascular. E, como benefícios psicossociais encontram-se o alívio da depressão, o aumento da autoconfiança e a melhora da auto-estima.
}

Isso evidencia a necessidade da redução dos níveis de sedentarismo entre a população. A atividade física praticada de forma regular é um importante aliado na 
conquista e manutenção de uma saúde mais positiva. Contudo tanto o conceito de atividade física quanto o de saúde pode variar de acordo com a cultura e isso precisa ser levado em consideração no momento do planejamento e da execução de ações de promoção da atividade física.

No campo da Educação Física, a atividade física é definida como todo movimento humano que dispenda uma quantidade de energia acima daquela observada em níveis de repouso. Na "cultura" da Educação Física esta é uma definição bem simples mas aos olhos de uma pessoa que não pertence a esse contexto, essa afirmação pode parecer algo sem sentido. Para alguns, atividade física pode ser entendida apenas como a prática de esportes, ou uma tarde de lazer, além de muitas outras definições que variam de acordo com uma realidade que envolve diversos aspectos sociais, culturais e econômicos.

Estas afirmações, geram reflexões a respeito do conceito da competência cultural, como uma habilidade fundamental para uma maior efetividade das intervenções daqueles envolvidos com a Educação Física escolar. De acordo com Helman (2009), a competência cultural implica uma capacidade dos profissionais e das organizações de saúde de compreender e responder efetivamente às necessidades culturais trazidas pelos pacientes às situações de cuidados de saúde. Ou seja, é a capacidade que o profissional tem, ou deveria ter, de entender as peculiaridades características da cultura carregada pela pessoa ou população alvo do atendimento em saúde, seja este preventivo ou curativo. $\mathrm{O}$ autor coloca ainda que a competência cultural sempre exige uma reflexão por parte dos profissionais da saúde da sua própria bagagem cultural, como preconceitos ou crenças particulares que podem interferir na administração bem-sucedida dos cuidados de saúde. Isso mostra uma relação íntima com o conceito de interculturalidade, evidenciando que o profissional de Educação Física, além de trabalhar de forma articulada com as culturas que o cercam através de seus clientes, precisa integrar e dialogar tais contextos com os seus próprios.

A partir daí, pode-se perceber um enorme leque de possibilidades em torno da prática da cultura corporal para se pensar em atividade física, cabendo ao profissional de Educação Física a tarefa de identificar a melhor maneira de se abordar o assunto dentro da realidade em que se está intervindo. Para que isso ocorra, o sentido da interculturalidade precisa estar incutido neste profissional que consequentemente 
possuirá uma maior competência cultural, auxiliando consideravelmente nas suas ações em educação e promoção da saúde entre os mais diversos contextos culturais.

Um exemplo da situação de visões diferentes da prática de atividades físicas pode ser observado com frequência nas aulas de Educação Física, principalmente do ultimo ciclo do ensino fundamental e no ensino médio. Os meninos geralmente gostam da prática do futebol ou futsal nas aulas e as meninas preferem outras modalidades. Primeiramente verifica-se uma diferença de visões de mundo, que também pode ser vista como uma diferença cultural entre os gêneros, principalmente uma diferença na cultura corporal de ambos. A partir daí, utilizando-se de uma abordagem intercultural, cabe ao profissional fazer com que estas duas realidades possam ser percebidas sob um ponto de vista diferente entre eles.

O professor pode explicar, por exemplo, que o futebol é um esporte que proporcionada integração entre os seus praticantes, estimula a cooperação entre os jogadores e que além disso é um excelente instrumento na aquisição de um condicionamento físico favorável a um boa condição de saúde, desde que praticado de forma correta e sem exageros. Do mesmo modo este mesmo professor, pode mostrar para os seus alunos os benefícios das demais modalidades esportivas, que possuem as mesmas vantagens do futebol do ponto de vista social e fisiológico, mas que isso ocorre de uma maneira diferente. Porém essa tentativa de entendimento e diálogo entre as duas realidades exemplificadas, não pode ser reduzida somente ao discurso. É preciso que que o professor de Educação Física faça com que essa percepção e entendimento do outro seja vivenciada de forma prática com experiências concretas. Por exemplo, para uma turma do $4^{\circ}$ ano do ensino fundamental em que os meninos limitam-se à prática do futebol e as meninas preferem a "queimada", provocando uma separação dos gêneros durante as aulas, pode-se promover a interação entre eles introduzindo a prática do handebol, explicando aos meninos que é muito parecido com o futebol, só que neste caso se joga com as mãos e afirmando para as meninas que é um jogo semelhante ao da "queimada", sendo que neste caso muda-se o alvo que passa a ser o gol.

Outro aspecto importante a ser levado em consideração pela Educação Física escolar é de que a criança ou o adolescente são possuidores de um corpo que se manifesta de diversas maneiras, sendo que grande parte dos benefícios advindos de um intervenção eficaz por parte da Educação Física serão refletidos neste corpo, tanto de 
forma fisiológica como psicológica. Afinal o corpo humano precisa estar em constante movimento. Um corpo hipocinético, sedentário, é mais propício ao desenvolvimento de distúrbios potencializadores de uma condição de saúde mais negativa. Para que este corpo se movimente, o seu "dono" precisa estar sob a influência de algum estímulo, seja intrínseco ou extrínseco. A Educação Física tem um grande potencial no desenvolvimento de ações que auxiliem este corpo a se manter ativo fisicamente com vistas a uma melhor qualidade de vida.

Em uma publicação de 2005, Rodrigues afirma que o corpo humano é socialmente construído, apresentando assim características dos fenômenos culturais, podendo variar entre as sociedades e dentro delas, e no tempo variando nas diferentes fases da vida. Isto mostra que as propostas oferecidas a este corpo por meio da Educação Física também devem variar em função do contexto social vivido por esse sujeito, utilizando-se de uma competência cultural para proporcionar uma prática de atividade física que melhor satisfaça as suas necessidades.

No entanto, isso não significa que essas práticas devem centrar-se somente no que é conhecido por esse sujeito, no que é peculiar do contexto sociocultural no qual o seu corpo foi concebido. Pelo contrário, uma ação intercultural pode ampliar as concepções de saúde e de práticas corporais dessa pessoa, aumentando o leque de possibilidades em relação à prática de atividades físicas, o que tende a aumentar as oportunidades de ações que promovam um estilo de vida ativo com foco na promoção da saúde.

A Educação Física escolar tem como um de seus papéis, o de fazer com que os seus alunos percebam a importância da manutenção de uma vida ativa. Este objetivo pode ser alcançado a partir de uma proposta que ofereça a esses sujeitos a oportunidade de vivenciar inúmeras formas da prática corporal, fazendo com que ele perceba a atuação do seu próprio ser, do seu corpo, da sua mente, dentro dessa realidade em que a a atividade física é vista como um instrumento poderoso para a manutenção da saúde.

Um outro importante fator a considerar, é que este estímulo em idades mais juvenis, aumenta as chances de que estes alunos tornem-se adultos com uma bagagem cultural, no que diz respeito à cultura corporal, mais ampla e diversificada aumentado o seu repertório de autoconhecimento e de valorização das novas experiencias fora da sua realidade sociocultural originária. A infância e adolescência são fases da vida onde a 
maioria dos comportamentos e atitudes são formados, refletindo para a idade adulta. Daí nota-se a importância do incentivo a prática regular de atividades físicas na juventude, acarretando numa perspectiva de presente e futuro para essa população com mais qualidade de vida e melhores condições de saúde. A esse respeito Nahas et al. (1995, p.59) colocam que:

Para aumentar a possibilidade de influenciar o comportamento futuro dos alunos, a Educação Física deve proporcionar a aquisição de conhecimentos sobre atividade física para o bem estar e a saúde em todas as idades, estimular atitudes positivas em relação aos exercícios físicos e a prática esportiva, propiciar independência e oportunizar experiências de atividades físicas agradáveis, que permitam a prática continuada, resguardando a percepção de auto-competência dos indivíduos.

A partir daí, o profissional de Educação Física deve pensar a sua prática como um meio poderoso de gerar influencias consideravelmente positivas na população, especialmente entre os mais jovens. Neste sentido Oliveira e Oliveira Júnior (2007), afirmam que a Educação Física, através de atividades sócio-psicomotoras constitui-se num fator de equilíbrio na vida das pessoas, expresso na interação entre, o espírito e o corpo, a afetividade e a energia, o indivíduo e o grupo, promovendo a totalidade desses sujeitos. Com isso, reflexões a respeito de uma Educação Física envolvida com as mais diversas formas de práticas corporais, com o objetivo de reconhecer, dialogar e valorizar as características daqueles que lhes são diferentes num contexto sociocultural, tornamse fundamentais no processo de construção da identidade profissional da Educação Física como uma disciplina integradora do corpo biológico e do corpo social, promovendo a interação destes entre si e com os demais da forma mais harmônica possível.

\section{CONSIDERAÇÕES FINAIS}

Percebe-se durante o texto a relevância dos temas abordados, mostrando que estes por si só já carregam uma importante significação no desenvolvimento das pessoas. Ao discutir sobre a articulação entre eles fica claro que as possibilidades de êxito no processo de formação de cidadãos mais críticos e socialmente conscientes em relação a si próprios e aos demais a sua volta ampliam-se consideravelmente. 
A convivência intercultural apresenta-se como um mecanismo, talvez o mais eficiente, na construção de um sujeito e, por conseguinte de uma sociedade que tenha a capacidade de enxergar o mundo sob uma perspectiva multidimensional, através de uma visão que pode ser entendida como transcultural.

A Educação Física escolar dentro desta concepção intercultural deve procurar transcender a uma realidade em que tais ideais deixem o campo reflexivo e passem a ser concretizadas de forma maciça no nosso país, visto que a diversidade cultural existente no Brasil ainda provoca inúmeras situações de desrespeito e preconceito com as culturas que habitam o mesmo espaço.

A utilização dos conceitos e propostas da interculturalidade não somente em ações educacionais, mas também naquelas que tem como foco a promoção da saúde por meio da atividade física, torna-se uma nova possibilidade de se pensar nas mais diversas práticas corporais carregadas pelas diferentes culturas, como uma forma efetiva de diálogo e interação das manifestações do corpo, sob um ponto de vista social e biológico.

Portanto, através deste estudo espera-se proporcionar um ponto de partida para a reflexão crítica daqueles envolvidos com atividades de promoção da saúde, especialmente os profissionais de Educação Física, sobre um aspecto importante desse processo que é o entendimento do outro de uma forma mais participativa em que se possa aprender com o diferente e com ele produzir coletivamente numa realidade em que diferentes pontos de vista sejam conhecidos e utilizados como base para a educação, a saúde, a qualidade de vida e para a cidadania.

\section{REFERÊNCIAS}

FLEURI, Reinaldo Matias. Intercultura e educação. Rev. Bras. Educ. n.23. Rio de Janeiro. mai-ago. 2003.

HELMAN, Cecil G. Cultura, saúde e doença. 5. ed. Porto Alegre: Artmed, 2009.

MATSUDO, Sandra Mahecha, et. al. Nível de atividade física da população do Estado de São Paulo: análise de acordo com o gênero, idade, nível socioeconômico, 
distribuição geográfica e de conhecimento. Rev. Bras. Ciên. e Mov. Brasília, v. 10, n. 4, p. 41-50, out. 2002.

NAHAS, Markus Vinícius, et al. Educação para atividade física e saúde. Revista Brasileira de Atividade Física e Saúde, Pelotas, v. 1, n. 1, p. 57-65, 1995.

NEIRA, Marcos Garcia. Educação Física na perspectiva cultural: proposições a partir do debate em torno do currículo e da expansão do Ensino Fundamental. Horizontes, Itatiba, v. 27, n. 2, p. 79-89, jul/dez, 2009.

NEIRA, Marcos Garcia. O currículo da Educação Física frente à diversidade cultural: um estudo de caso. In: $31^{\text {a }}$ Reunião Anual da Associação Nacional de Pós-graduação em Educação, 2008, Caxambu. Anais da 31 ${ }^{\mathbf{a}}$ Reunião Anual da Anped. Rio de Janeiro: Anped, 2008. v. 1 CD. p. 1-18.

OLIVEIRA, Rogério Cruz. DAOLIO, Jocimar. Educação intercultural e educação física escolar: possibilidades de encontro. Pensar a Prática, Goiânia, v. 14, n. 2, p. 1-11, maio/ago. 2011.

RANGEL, Irene Conceição Andrade, et al. Educação Física Escolar e multiculturalismo: possibilidades pedagógicas. Motriz, Rio Claro, v.14 n.2 p.156-167, abr/jun, 2008.

RODRIGUES, José Carlos. Os corpos na Antropologia. In: MINAYO, Maria Cecília de S., JÚNIOR, Carlos E. A. (Org.) Coimbra. Críticas e Atuantes Ciências Sociais e Humanas em Saúde na América Latina. Rio de Janeiro: Editora FIOCRUZ, p. 157-182, 2005. 